\title{
The effect of curcumin and PI3K/Akt inhibitor on monosodium glutamate-induced rat thymocytes toxicity
}

\author{
Miodrag Vucic ${ }^{1}$, Irena Cojbasic ${ }^{1}$, Jelena Vucic ${ }^{2}$ and Voja Pavlovic ${ }^{3}$ \\ ${ }^{1}$ Clinic of Hematology and Clinical Immunology, Medical Faculty University of Nis, Nis, Serbia \\ ${ }^{2}$ Clinic of Pediatrics, Medical Faculty University of Nis, Nis, Serbia \\ ${ }^{3}$ Institute of Physiology, Medical Faculty University of Nis, Nis, Serbia
}

\begin{abstract}
Monosodium glutamate (MSG), the sodium salt of glutamic acid, is widely used in modern nutrition as flavor enhancer. However, it has been shown that curcumin has ability to induce apoptosis in the cells of the immune system. In the present study, we evaluate the potential protective effects of curcumin in MSG-induced apoptosis and signaling pathway which may be involved. Rat thymocytes were treated with increased $(1,10,50 \mathrm{mM}) \mathrm{MSG}$ concentrations and/or curcumin $(3 \mu \mathrm{M})$. Cell apoptosis rate, reactive oxygen species (ROS) production, mitochondrial membrane potential (MMP), Bcl-2, Bax protein expression and caspase-3 activity were determined after 24 hours of incubation. Treatment with MSG resulted with increased apoptosis, ROS production and caspase-3 activity, followed with decreased MMP and Bcl-2/Bax protein ratio. Inhibition of caspase-3 and caspase-9 activity reduced cell apoptosis, indicating the involvement of mitochondrial apoptotic pathway. Co-treatment with curcumin markedly reduced apoptosis and ROS production, together with increased MMP and Bcl2/Bax protein ratio. Inhibition of PI3K/Akt signaling pathway abolished protective effect of curcumin in MSG-induced toxicity in rat thymocytes. Obtained findings suggest that curcumin may attenuate the MSG-induced apoptosis through PI3K/Akt signaling pathway which could be useful in preventing the potential deficiencies in T cell-mediated immunity.
\end{abstract}

Key words: Monosodium glutamate - Curcumin - Apoptosis - PI3K signaling pathway

\section{Introduction}

Monosodium glutamate (MSG), the sodium salt of glutamic acid (GA), is a common food additive in developed world, usually used as a flavor enhancer (Sharma 2015). Due to its wide distribution, chronic oral MSG intake leads to accumulation and rise of the GA in blood (Paul et al. 2012). GA is one of the most abundant excitatory neurotransmitter and exerts its effects through ionotropic (iGluR) and metabotropic (mGluR) glutamate receptors. iGluR (NMDA, AMPA and kainite receptors) form ion channels that are activated by glutamate, while mGluR (mGluR1-mGlur8) activate or inhibit cytoplasmic enzymes through $\mathrm{G}$ proteins (Reiner et al. 2015). In recent years, several studies have

Correspodence to: Voja Pavlovic, Institute of Physiology, Medical Faculty University of Nis, Bulevar Dr. Zorana Djindjica, 81, 18000 Nis, Serbia

E-mail:vojapav@yahoo.com documented the presence of glutamate receptors in different non-neuronal cells (Hinoi et al. 2004; Skerry and Genever 2001). Glutamate receptors have been identified in the cells of the immune system, including human lymphocytes (Ganor et al. 2003), mice (Storto et al. 2000) and rat (Rezzani et al. 2003) thymocytes. Our previous results demonstrate that MSG was able to induce rat thymocytes apoptosis in vitro (Pavlovic et al. 2007a) and in vivo (Pavlovic et al. 2007b) conditions. Pro-apoptotic ability of MSG was also documented in B cells with potential to develop secondary immunological consequences (Jovic et al. 2009).

Curcumin is a polyphenol derived from the rhizome of the plant Curcuma longa and is a comonly used seasoning spice and medical plant in Asia for thousands of years. Due to its anti-inflamatory and anti-oxidant properties, curcumin has been shown to have protective role in different organs (Goel and Aggarwal 2010) and treatment of several disorders (Guan et al. 2016). Recent studies have demonstrated that curcumin possesses immunoregulatory role (Nagpal 
and Sood 2013) as well to may prevent toxicity in different cells of the immune system against various stimuli (Sebastia et al. 2011; Pavlovic et al. 2016). It has been suggested that mechanism for protective effects of curcumin includes its ability to normalize $\mathrm{Bcl}-2 / \mathrm{Bax}$ protein ration in the cells (Yu et al. 2016). In addition, previous studies reported that modulatory role of curcumin in lymphocytes have been mediated through PI3K/Akt signaling pathway (Li et al. 2012; $\mathrm{Yu}$ et al. 2016). Therefore, in the present study, we tested whether curcumin may attenuate the MSG-induced toxicity in rat thymocytes along with the involvement of PI3k/Akt signaling pathway.

\section{Material and Methods}

\section{Animals}

Experiments were performed on adult male Wistar rats (190-220 g), 9-11 weeks old, bread at the Vivarium of the Institute of Biomedical Research, Medical Faculty, Nis, under conventional laboratory conditions and in accordance with national animal protection guidelines. All procedures were performed in line with the recommendations for the proper use and care of laboratory animal and confirmed to the European Communities Council Directive of November 1986 (86/609/EEC).

\section{Materials}

Culture medium (CM) was prepared using RPMI 1640 (Sigma-Aldrich, St. Louis, 16 Mo., USA) according to the manufacturer's instructions. CM contained 25 mM HEPES, $2 \mathrm{mM}$ glutamine, penicillin $(100 \mathrm{U} / \mathrm{ml})$, streptomycin (100 $\mu \mathrm{g} / \mathrm{ml}$ ) and $10 \%$ fetal calf serum (FCS).

Rhodamine 123, 2',7'-dichlorofluorescin diacetate (H2DCF-DA), wortmannin (a PI3K inhibitor), Z-VADFMK, Z-LEHD-FMK, Z-IETD-FMK and curcumin were purchased from Sigma-Aldrich (St. Louis, Mo., USA). Caspase-3 colorimetric assay was obtained from R\&D Systems (Minneapolis, USA). Monosodium glutamate was purchased from Fluka, Chemika AG (Buchs, Switzerland).

\section{Preparation of thymocytes}

Rat thymocytes were isolated as described previously (Pavlovic et al. 2007). Briefly, thymus was extirpated using sterile technique and placed in CM with 10\% FCS. Thymocytes were released by teasing the thymus through a steel mesh. Cell suspensions were filtered through sterile nylon filter to remove the stroma and the cells were washed twice with $\mathrm{CM} / 10 \% \mathrm{FCS}$. The viability of the isolated cells, as determined by trypan blue dye exclusion test, was always over $94 \%$. Isolated thymocytes were counted and adjusted to a density of $1 \times 10^{6}$ cells $/ \mathrm{ml}$.

\section{Cell culture}

Isolated rat thymocytes were cultivated in 96-well roundbottom plates (NUNC, Aarhus, Denmark), containing a $100 \mu$ of cell suspension $\left(1 \times 10^{5}\right.$ cells $)$ in each well. Cells were cultured with increasing concentrations $(1,10,50 \mathrm{mM})$ of MSG with or without curcumin $(3 \mu \mathrm{M})$. Control cells were treated with appropriate amounts of vehicle alone, diluted in CM. All cell cultured are done in triplicates and cultivated for $24 \mathrm{~h}$ in an incubator (Galaxy, Wolf Laboratories, USA) with $5 \% \mathrm{CO}_{2}$ at $37^{\circ} \mathrm{C}$.

When indicated, rat thymocytes were cultured in either the presence or absence of wortmannin, a PI3K inhibitor, at a final concentration of $10 \mu \mathrm{M}$ (Lindgren et al. 2011), Z-VAD-FMK, a pan-inhibitor of caspases, at final concentration of $10 \mu \mathrm{M}$ (Nishimura et al. 2008), Z-IETD-FMK, caspase- 8 inhibitor, at final concentration of $20 \mu \mathrm{M}$ (Zhou et al. 2013) or Z-LEHD-FMK, caspase-9 inhibitor, at final concentration of $20 \mu \mathrm{M}$ (Park et al. 2013).

Curcumin was dissolved in DMSO as a stock solution. The stock solution was stored at $-20^{\circ} \mathrm{C}$ and diluted in $\mathrm{CM}$ before use. The final concentration of DMSO, applied to the cells, was less than $0.5 \%$. Concentration of curcumin, used in our study, was chosen due to our recently published findings (Pavlovic et al. 2016) and previous study results in rat thymocytes (Koizumi et al. 2011), which showed that $3 \mu \mathrm{M}$ was the lowest concentration which was not able to induce any cytotoxic actions in rat thymocytes, while MSG concentrations were adopted from previous reports (Pavlovic et al. 2007; Jovic et al. 2009) regarding the in vitro effect of this compound on thymocytes toxicity.

\section{Apoptotic DNA analysis}

Cells undergoing apoptosis were identified by their reduced relative nuclear DNA content, as described earlier (Nicoletti et al. 1991). The frequency of apoptotic cells were detected using an Epics XL flow cytometer (Coulter, Krefeld Germany) as a reduction in fluorescence of the DNA-binding dye Propidium Iodide (PI-Santa Cruz, Biotechnology, Santa Cruz, CA, USA) in apoptotic nuclei. The percentage of cells with subdiploid DNA content (apoptotic cells) was determined and presented as a ratio of control for further comparison.

Measurement of intracellular reactive oxygen species (ROS) production

A redox-sensitive probe (H2DCF-DA) was used to determine changes in overall cellular ROS levels, as previously 
reported (Boldogh et al. 2003; Das et al. 2005). Briefly, after cultivation period ended, cell suspension was loaded with $5 \mu \mathrm{l}$ of $\mathrm{H} 2 \mathrm{DCF}-\mathrm{DA}$ for 15 minutes at $37^{\circ} \mathrm{C}$. The change in fluorescence (excitation $485 \mathrm{~nm}$; emission $530 \mathrm{~nm}$ ) was evaluated by flow cytometry, as described earlier (Singh et al. 2013). For each sample, basal fluorescence intensity values were subtracted from those obtained after different treatments and results were presented as ratio of mean fluorescence intensity for further comparison.

\section{Determination of mitochondrial membrane potential (MMP)}

Changes of MMP of rat thymocytes were evaluated by uptake of lipophilic cation Rhodamine 123 into mitochondria, as previously described (Wang et al. 2007). Briefly, treated cells were incubated with Rhodamine $123(5 \mu \mathrm{g} / \mathrm{ml}$ as final concentration) for 60 minutes in the dark at $37^{\circ} \mathrm{C}$. Thymocytes were harvested and resuspended in phosphate-buffered saline. The fluorescence of intracellular Rhodamine 123 was determined by flow cytometry, as published earlier (Singh et al. 2013). For each sample, basal intensity values were subtracted from those obtained after different treatments and results were presented as ratio of mean fluorescence intensity for further comparison.

\section{Flow cytometric evaluation of Bcl-2 and Bax expression}

The expression was evaluated as we described previously (Pavlovic et al. 2007) by using anti-Bcl-2FITC (Santa Cruz, Biotechnology, Santa Cruz, CA, USA) and anti-BaxFITC (Santa Cruz, Biotechnology, Santa Cruz, CA, USA) mouse monoclonal antibodies. Labeled cells were fixed in $4 \%$ formalin and analyzed (5000 analyzed cells/per sample) on flow cytometer. Non-specific binding was detected by the control cells, which were incubated by the irrelevant antibody.

\section{Caspase-3 activity assay}

The enzymatic activity of the caspase- 3 was determined by a colorimetric assay (by using the chromogenic substrate DEVD-pNA) from R\&D Systems (Minneapolis, USA), according to the manufacturer's protocol. The reaction was measured by determining the change in absorbance at $405 \mathrm{~nm}$. The activity was expressed as fold change of treated cell over the non-treated cells. The background values were subtracted from the experimental results before calculation the fold induction.

\section{Statistical analysis}

Results are presented as mean \pm SD. The comparisons among groups were carried out using the analysis of vari- ance (ANOVA) coupled to the Dunnett's post hoc test and Student's $t$-test. $p<0.05$ was considered significant.

\section{Results}

We have used flow cytometric analysis to detect the appearance of subdiploid peak which indicates the hypodiploid DNA of apoptotic cells. Exposure to increasing MSG concentrations resulted in dose-dependent increase of cells with hypodiploid content. A significant increase of apoptotic cells was detected following treatment with $1 \mathrm{mM}(p<0.05)$, $10 \mathrm{mM}(p<0.01)$ and $50 \mathrm{mM}(p<0.01)$ MSG (Figure 1A, $1 B)$. On the other hand, curcumin application significantly $(p<0.05)$ decreased total number of hypodiploid cells after MSG treatment (Figure 1A).

To evaluate the potential role of caspases in MSG-induced apoptosis in thymocytes, next we examined the effects of different caspase inhibitors, including pan caspase inhibitor Z-VAD-FMK, caspase-9 inhibitor Z-LEHD-FMK and caspase-8 inhibitor Z-IETD-FMK on cell apoptosis. Thymocytes pretreatment with Z-VAD-FMK markedly suppressed MSG-induced cell apoptosis, proposing that MSG-induced apoptosis mainly occurs in caspase-dependent manner (Figure 1C). Further, caspase-9 inhibitor significantly $(p<0.01)$ attenuated MSG-induced thymocytes apoptosis, while caspase- 8 inhibitor failed to significantly inhibit apoptotic cell rate (Figure 1C), indicating that intrinsic apoptosis pathway plays key role in MSG-induced apoptosis in rat thymocytes. These findings correspond with mitochondrial dysfunction, observed later in the study.

Having in mind that ROS production and MMP disturbances have important role in cell apoptosis, in next set of experiments we evaluated possible effects of MSG and curcumin on ROS and MMP levels in rat thymocytes. Results presented in Figure 2A, demonstrate significantly ( $1 \mathrm{mM}$, $p<0.05 ; 10 \mathrm{mM}, 50 \mathrm{mM}, p<0.01$ ) increased H2DCF-DA fluorescence intensity, indicating the increase in intracellular ROS production after MSG treatment in thymocytes. Furthermore, thymocytes exposure to MSG resulted with significantly ( $1 \mathrm{mM}, p<0.05 ; 10 \mathrm{mM}, 50 \mathrm{mM}, p<0.01$ ) decreased MMP, as evaluated by intracellular Rhodamine fluorescence intensity (Figure 2B). Moreover, co-incubation with MSG and curcumin significantly attenuated altered MMP (1 mM, $p<0.01 ; 10 \mathrm{mM}, 50 \mathrm{mM}, p<0.05)$ and ROS $(1 \mathrm{mM}, 10 \mathrm{mM}, 50 \mathrm{mM}, p<0.05)$ production in thymocytes (Figure 2A, 2B).

To further evaluate the role of intrinsic related apoptosis factors, we next examined whether Bcl-2 and Bax proteins are involved in apoptotic process of rat thymocytes exposed to MSG and curcumin. Obtained results show that MSG significantly ( $1 \mathrm{mM}, p<0.05 ; 10 \mathrm{mM}, p<0.01,50 \mathrm{mM}, p<$ 0.01 ) downregulated $\mathrm{Bcl}-2$ protein expression (Figure $3 \mathrm{~A}$ ) 

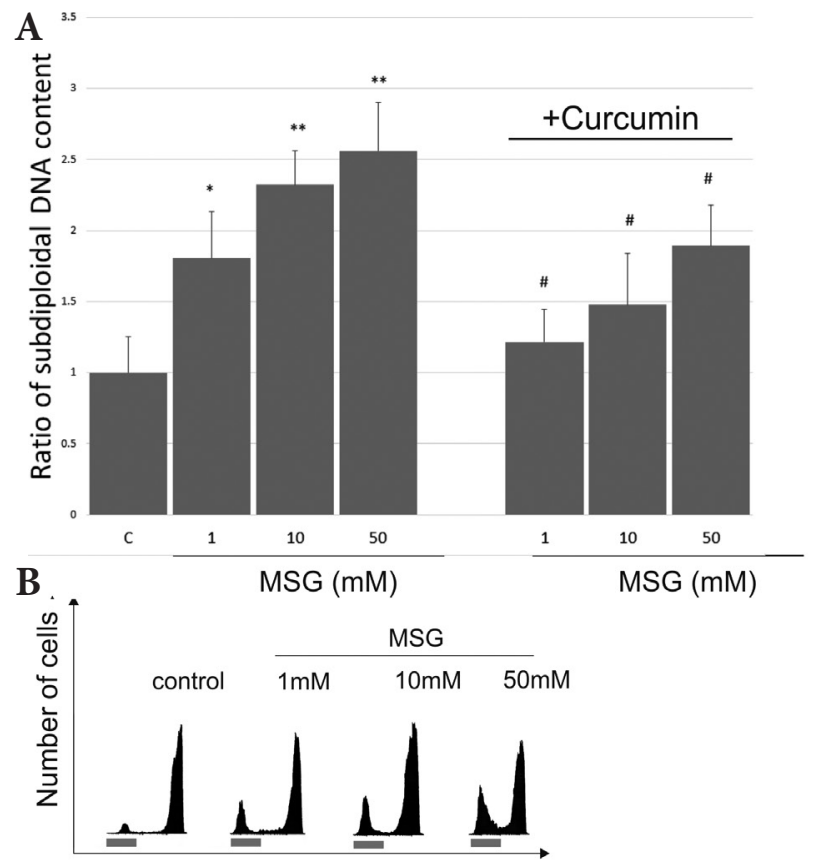

Intensity of propidium iodide fluorescence

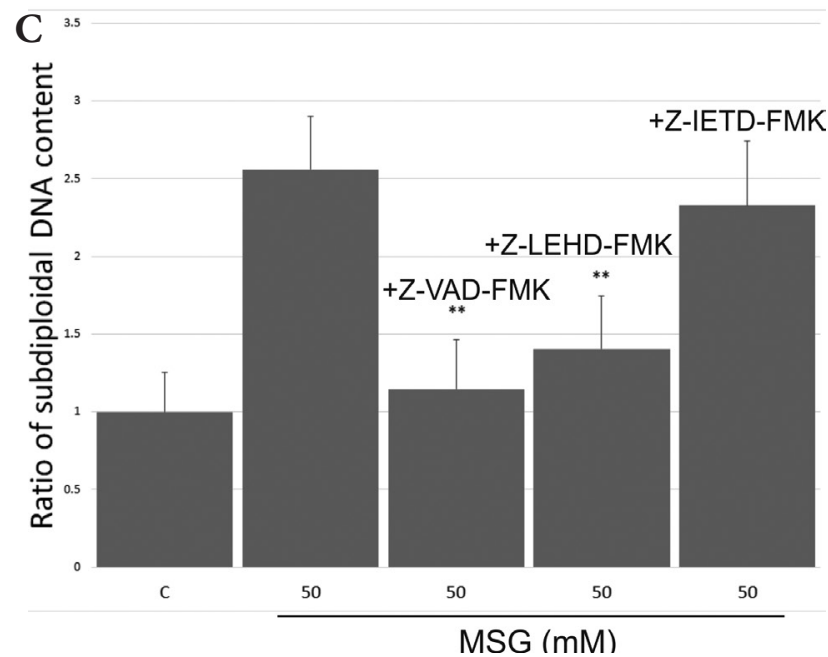

Figure 1. Effect of MSG, curcumin and different caspase inhibitors (Z-VAD-FMK, Z-LEHD-FMK, Z-IETD-FMK) on rat thymocytes toxicity. A. Rat thymocytes cultured with increasing MSG concentrations $(1,10,50 \mathrm{mM})$ with or without curcumin $(3 \mu \mathrm{M})$ for 24 hours. Apoptosis was evaluated by determination the cells with subdiploid DNA content. Data were expressed as ratio for control for further comparison. ${ }^{*} p<0.05,{ }^{* *} p<0.01$ compared to the control cells; ${ }^{*} p<$ 0.05 compared to the MSG-treated cells. B. Representative histograms of the cells treated with increasing $(1,5$ and $50 \mathrm{mM})$ MSG concentrations. The bar under the histogram indicates the population of the cells with subdiploid DNA content. C. Rat thymocytes cultured with MSG (50 $\mathrm{mM}$ ) without or with Z-VAD-FMK (pan-inhibitor of caspases), Z-LEHD-FMK (caspase-9 inhibitor) and Z-IETD-FMK (caspase-8 inhibitor). Apoptosis was evaluated by determination the cells with subdiploid DNA content. Data were expressed as ratio for control for further comparison. ${ }^{\star *} p<0.01$ compared to the MSG-treated cells. Data are means \pm SD. C, control; MSG, monosodium glutamate. in rat thymocytes, as evaluated by flow cytometric analysis. As shown in Figure 3A, curcumin application significantly (1 mM, $10 \mathrm{mM}, 50 \mathrm{mM}, p<0.05$ ) restored Bcl-2 protein expression in rat thymocytes, suggesting the involvement of intrinsic apoptotic pathway in this model of cytotoxicity. On

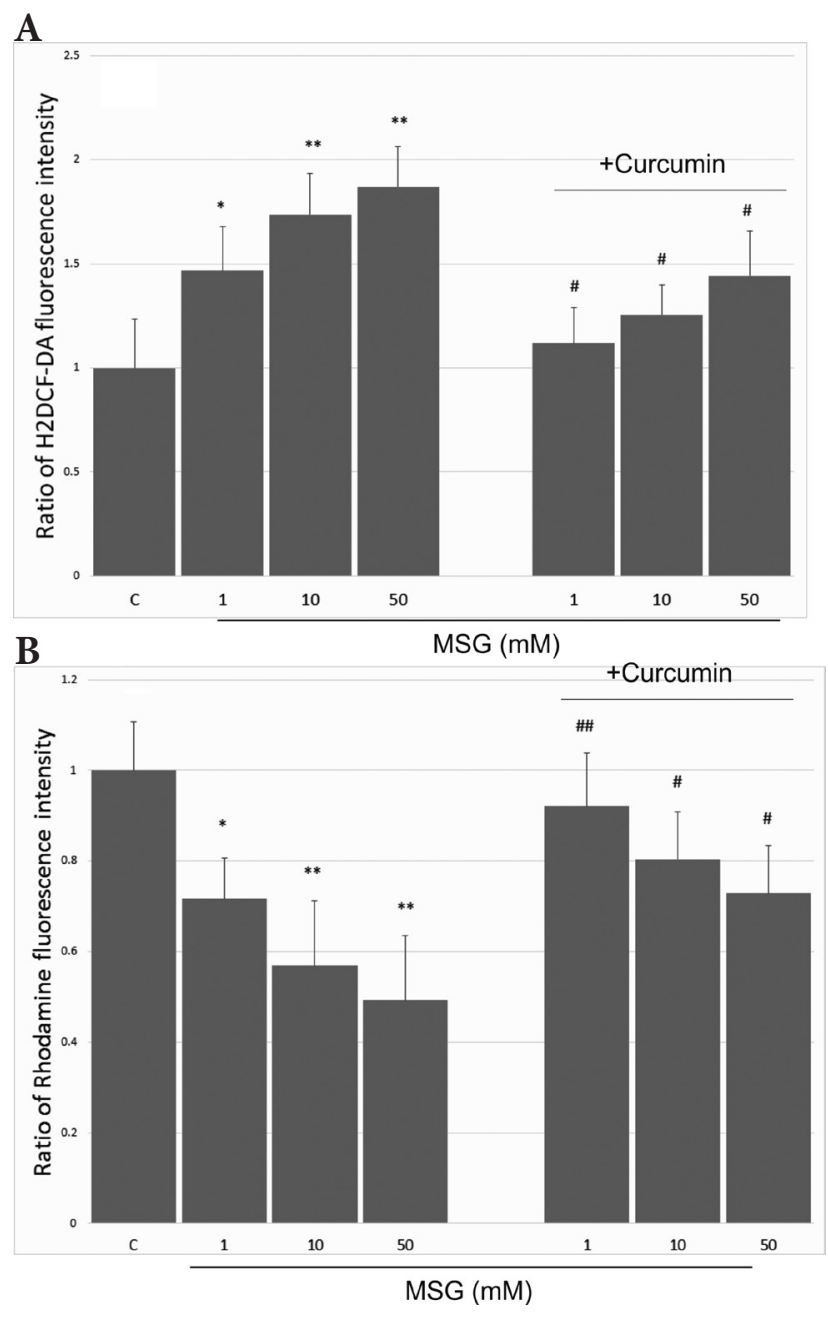

Figure 2. Effect of MSG and curcumin on ROS production and MMP level in rat thymocytes. A. Rat thymocytes were cultured with increasing MSG concentrations $(1,10,50 \mathrm{mM})$ with or without curcumin $(3 \mu \mathrm{M})$ for 24 hours. ROS production was evaluated by using redox sensitive probe (H2DCF-DA). Data were expressed as ratio for control for further comparison. ${ }^{*} p<0,05$, ${ }^{* *} p<0.01 \mathrm{com}-$ pared to the control cells; ${ }^{\#} p<0.05$ compared to the MSG-treated cells. B. Cells were cultured with increasing MSG concentrations (1, $10,50 \mathrm{mM})$ with or without curcumin $(3 \mu \mathrm{M})$ for 24 hours. MMP was evaluating by uptake of lipophilic cation Rhodamine 123. Data were expressed as ratio for control for further comparison. ${ }^{\star} p<$ $0,05,{ }^{* *} p<0.01$ compared to the control cells; ${ }^{\#} p<0.05,{ }^{\# \#} p<$ 0.01 compared to the MSG-treated cells. Data are means \pm SD. C, control; MMP, mitochondrial membrane potential, MSG, monosodium glutamate; ROS, reactive oxygen species. 
the other hand, no significant changes of Bax protein expression were detected in rat thymocytes, following the treatment with MSG or MSG and curcumin together (Figure 3A).

Phosphatidylinositol 3-kinase (PI3K) signaling pathway has important role in survival and apoptosis in different cell types. Therefore, in next experiments we evaluated the involvement of PI3K signaling pathway in antiapoptotic activities of curcumin in MSG-induced rat thymocytes apoptosis. Current study results showed that wortmannin (a PI3K inhibitor) markedly inhibited $(p<0.05)$ antiapoptotic effects of curcumin against MSG-induced rat thymocytes toxicity, as evaluated by caspase- 3 activity (Figure 3B). These findings indicate a possible role for PI3K signaling pathway in the curcumin-mediated protection of rat thymocytes exposed to MSG. However, since the inhibition was not complete, we are not able to neglect the activation of other multiple signaling pathways.

\section{Discussion}

In the current study, by using flow cytometric analysis, we showed that MSG application was able to induce rat thymocytes apoptosis in a dose-dependent manner. Inhibition experiments revealed that caspase- 3 and caspase-9 inhibitor could markedly inhibit MSG-induced apoptotic cell rate while caspase- 8 inhibitor did not have such role, suggesting that MSG-induced apoptosis mainly occurs in caspasedependent manner and through mitochondrial pathway of apoptosis. In line with this observation, rat thymocytes exposure to MSG resulted with increased ROS production, MMP collapse and downregulated $\mathrm{Bcl}-2$ protein expression. The proapoptotic potential of MSG has been documented earlier in rat thymocytes (Pavlovic et al. 2007a, 2007b) and other immune cells (Jovic et al. 2009) and here, we demonstrate, for the first time, the involvement of intrinsic apoptotic pathway in this model of cytotoxicity. In addition, MSG did not alter Bax protein but downregulated $\mathrm{Bcl}-2$ protein, proposing that $\mathrm{Bcl}-2 / \mathrm{Bax}$ protein ratio, rather than $\mathrm{Bcl}-2$ and Bax protein itself, is important in MSG-induced rat thymocytes apoptosis. The existence of glutamate receptor (mGluR5) is well documented in rat thymocytes (Rezzani et al. 2003). mGluR5 activation leads to excessive uptake of $\mathrm{Ca}^{2+}$ into mitochondria which results with release of proapoptotic factors and increased ROS generation (Miglio et al. 2005). Intensive ROS generation and depleted Bcl-2/ Bax protein ratio may trigger mitochondrial transition pore to open and start apoptotic process, by releasing different proapoptotic factors into cytosol (Guo et al. 2013). These findings correspond with obtained increased ROS production and mitochondrial dysfunction observed in our study.

To further investigate the hypothesis that curcumin may modulate MSG-induced apoptosis in rat thymocytes, cells were co-incubated with MSG and curcumin for 24 hours. Obtained results showed that curcumin application significantly restored MSG-induced thymocytes apoptosis in all tested concentrations. Mitochondria are the most vulnerable targets of ROS and the loss of MMP represents the early event in mitochondrial pathway of apoptosis (Dai et al. 2016).

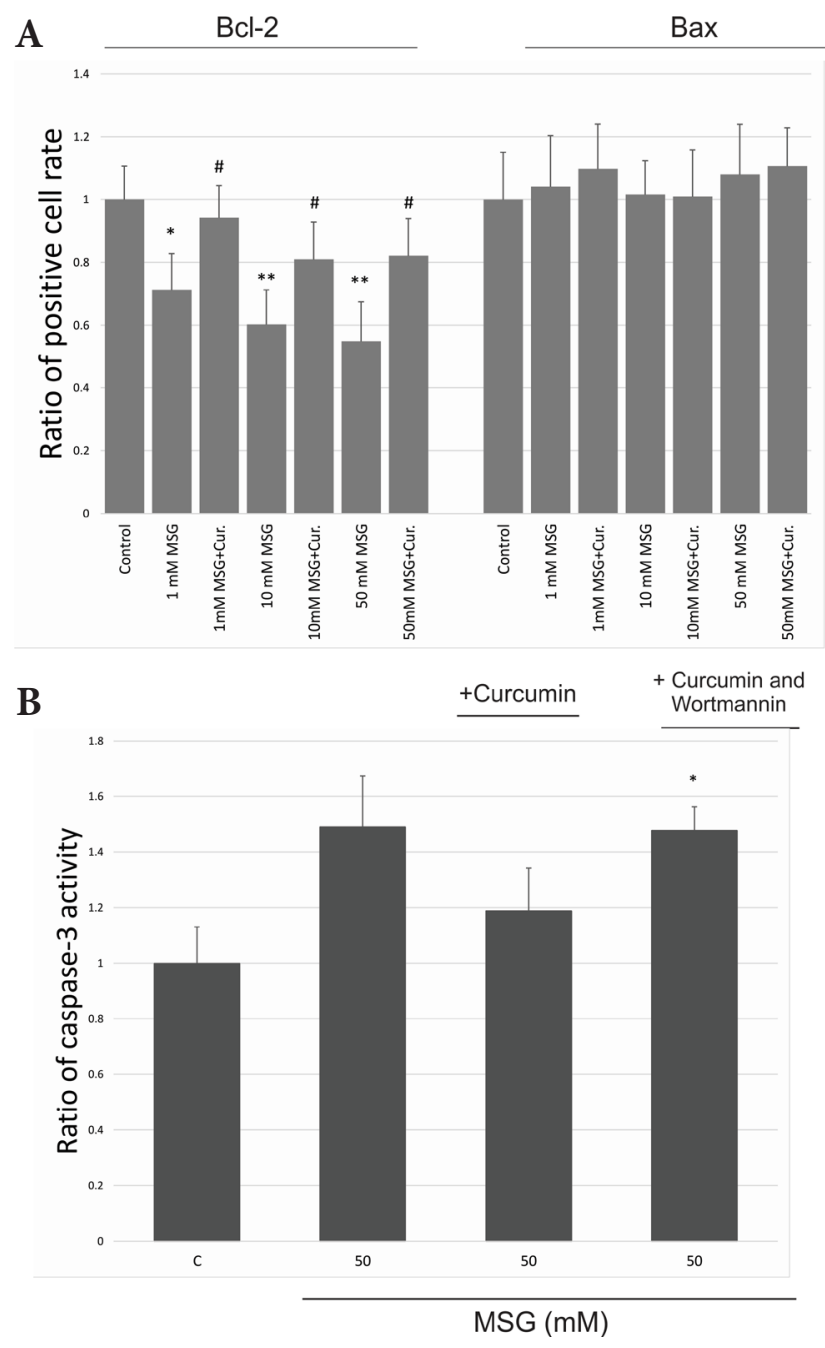

Figure 3. Effect of MSG, curcumin and wortmannin (a PI3K inhibitor) on Bcl-2, Bax protein expression and caspase-3 activity. A. Cells were treated with increasing MSG concentrations (1, 10, 50 $\mathrm{mM})$ with or without curcumin $(3 \mu \mathrm{M})$ for 24 hours. Bcl-2 and Bax protein expression (cell positive rate) was evaluated by flow cytometric analysis. Data were expressed as ratio for control for further comparison. ${ }^{\star} p<0.05,{ }^{* *} p<0.01$ compared to the control cells; ${ }^{\#} p<0.05$ compared to the MSG-treated cells. B. Rat thymocytes were cultivated with MSG (50 mM) with or without curcumin and wortmannin for 24 hours. Caspase- 3 activity was determined by using chromogenic substrate DEVD-pNA. ${ }^{*} p<0.05$ compared to the cell treated with MSG and curcumin. Data are means \pm SD. C, control; Cur, curcumin; MSG, monosodium glutamate. 
Altered MMP may lead to transformation of mitochondrial permeability, with resulting release of cytochrome $c$ and activation of caspase- 9 and caspase- 3 (Su et al. 2007), suggesting that by preserving mitochondrial function activation of mitochondrial apoptosis pathway could be prevented (Fan et al. 2016). In the present study, we observed that curcumin attenuated ROS production, restored MMP and upregulated of $\mathrm{Bcl}-2 / \mathrm{Bax}$ protein ratio in rat thymocytes after MSG treatment. Bcl-2 and Bax proteins have ability to influence caspase activation by controlling the release of cytochrome $\mathrm{c}$ from mitochondria. The release of cytochrome $c$ is associated with the increase of Bax and decrease of Bcl-2 protein (Xue et al. 2014). In line with these observations, several studies showed that curcumin was able to suppress mitochondria pathway of apoptosis in different cell types, by modulating Bcl-2/Bax protein ratio (Liu et al. 2011; Xue et al. 2014; Dai et al. 2016; Sadek et al. 2016). Taking into account our results, it seems that cells treatment with curcumin could be beneficial in preventing the MSG-induced apoptosis in rat thymocytes by suppressing mitochondrial apoptotic pathway.

PI3K/Akt signaling pathway has a key role in regulating different cell activities, including cell survival and apoptosis (Li et al. 2012). It exerts anti-apoptotic activity by preventing the release of cytochrome $\mathrm{c}$ from mitochondrial and it is involved in process of upregulation of $\mathrm{Bcl}-2$ protein (Guo et al. 2013; Fan et al. 2016). In the present study, we found that wortmannin (a PI3K inhibitor) significantly abolished protective effect of curcumin against the MSG-induced rat thymocytes apoptosis, as evaluated by caspase- 3 activity. These findings correspond with restored MMP and inhibited ROS production in rat thymocytes following the curcumin application. However, since the PI3K/Akt inhibition did not completely abolished protective effect of curcumin in rat thymocytes, other signaling pathways cannot be neglected. Similar results were obtained in different studies, showing that protective effect of curcumin is mainly mediated through PI3K/Akt signaling pathway in mitochondrialinduced apoptosis (Li et al. 2012; Rashid and Sil 2015). However, we may not neglect that usage of more precise methods, used for thymocytes apoptosis detection (Betsuyaku et al. 2017), might resolve many points in thymocytes signaling, but this requires further analysis. Taken together, our results suggest that protective effect of curcumin is mainly mediated through PI3K/Akt signaling pathway in MSG-induced apoptosis in rat thymocytes.

In summary, our results indicate that rat thymocytes exposure to MSG resulted with caspase-dependent cell apoptosis, which occurs through mitochondrial pathway. Also, current study results demonstrate that curcumin was able to protect rat thymocytes from MSG-induced apoptosis, mainly though PI3K/Akt signaling pathway. These findings could potentially provide the basis of curcumin as a potential therapeutic strategy for individuals exposed to food additives and prevent potential deficiencies in $\mathrm{T}$ cellmediated immunity.

Conflict of interests. None declared.

\section{References}

Betsuyaku T, Eid N, Ito Y, Tanaka Y, Otsuki J, Kondo Y (2017): Etanol enhances thymocyte apoptosis and autophagy in macrophages of rat thymi. Histol. Histopathol. 32, 963-975

Boldogh I, Roy G, Lee MS, Bacsi A, Hazra TK, Bhakat KK, Das GC, Mitra S (2003): Reduced DNA double strand breaks in chlorambucil resistant cells are related to high DNAPKCs activity and low oxidative stress. Toxicology 193, 137-152 https://doi.org/10.1016/j.tox.2003.08.013

Dai C, Li D, Gong L, Xiao X, Tang S (2016): Curcumin ameliorates furazolidone-induced DNA damage and apoptosis in human hepatocyte L02 cells by inhibiting ROS production and mitochondrial pathway. Molecules 21, E1061 https://doi.org/10.3390/molecules21081061

Das A, Hazra TK, Boldogh I, Mitra S, Bhakat KK (2005): Induction of the human oxidized base-specific DNA glycosylase Neil1 by reactive oxygen species. J. Biol. Chem. 280, 35272-35280 https://doi.org/10.1074/jbc.M505526200

Fan YL, Li HC, Zhao W, Peng HH, Huang F, Jiang WH, Xu SY (2016): Curcumin attenuated bupivacaine-induced neurotoxicity in SH-SY5Y cells via activation of the Akt signaling pathway. Neurochem. Res. 41, 2425-2432 https://doi.org/10.1007/s11064-016-1955-4

Ganor Y, Besser M, Ben-Zakay N, Unqer T, Levite M (2003): Human T-cells express a functional ionotropic glutamate receptor GluR3, and glutamate by itself triggers integrin-mediated adhesion to laminin and fibronectin and chemotactic migration. J. Immunol. 170, 4362-4372

https://doi.org/10.4049/jimmunol.170.8.4362

Goel A, Aggarwal BB (2010): Curcumin the golden spice from Indian saffron, is a chemosensitizer and radiosensitizer for tumors and chemoprotector and radioprotector for normal organs. Nutr. Cancer 62, 919-930

https://doi.org/10.1080/01635581.2010.509835

Guan F, Ding Y, Zhang Y, Zhou Y, Li M, Wang C (2016): Curcumin suppresses proliferation and migration of MDA-MB-231 breast cancer cells through autophagy-dependent Akt degradation. PLoS One 11, e0146553 https://doi.org/10.1371/journal.pone.0146553

Guo LD, Chen XJ, Hu YH, Yu ZJ, Wang D, Liu JZ (2013): Curcumin inhibits proliferation and induces apoptosis of human colorectal cancer cells by activating the mitochondria apoptotic pathway. Phytother. Res. 27, 422-430 https://doi.org/10.1002/ptr.4731

Hinoi E, Takarada T, Ueshima T, Tsuchihashi Y, Yoneda Y (2004): Glutamate signaling in peripheral tissues. Eur. J. Biochem. 271, 1-13 https://doi.org/10.1046/j.1432-1033.2003.03907.x

Jovic Z, Veselinovic M, Vasic K, Stankovic-Djordjevic D, Cekic S, Milovanovic M, Sarac M (2009): Monosodium glutamate 
induces apoptosis in naive and memory human B cells. Bratisl. Lek. Listy. 110, 636-640

Koizumi K, Kawanai T, Hashimoto E, Kanbara Y, Masuda T, Kanemaru K, Okano Y, Oyama Y (2011): Cytometric analysis on cytotoxicity of curcumin on rat thymocytes: Proapoptotic and antiapoptotic actions of curcumin. Toxicol. In Vitro 25, 985-990

https://doi.org/10.1016/j.tiv.2011.03.010

Li WX, Chen SF, Chen LP, Yang GY, Li JT, Liu HZ, Zhu W (2012): Thimerosal-induced apoptosis in mouse $\mathrm{C} 2 \mathrm{C} 12$ myoblast cells occurs through suppression of the PI3K/Akt/ survivin pathway. PLoS One 7, e49064 https://doi.org/10.1371/journal.pone.0049064

Lindgren A, Pavlovic V, Flach C.F, Sjöling A, Lundin S (2011): Interferon-ga mMa secretion is induced in IL-12 stimulated human NK cells by recognition of Helicobacter pylori or TLR2 ligands. Innate Immun. 17, 191-203 https://doi.org/10.1177/1753425909357970

Liu W, Fan Z, Han Y, Lu S, Zhang D, Bai X, Xu W, Li J, Wang $H$ (2011): Curcumin attenuates peroxynitrite-induced neurotoxicity in spiral ganglion neurons. Neurotoxicology 32, 150-157 https://doi.org/10.1016/j.neuro.2010.09.003

Miglio G, Varsaldi F, Dianzani C, Fantozzi R, Lombardi G (2005): Stimulation of group I metabotropic glutamate receptors evokes calcium signals and c-jun and c-fos gene expression in human T cells. Biochem. Pharmacol. 70, 189-199 https://doi.org/10.1016/j.bcp.2005.04.038

Nagpal M, Sood S (2013): Role of curcumin in systemic and oral health: an overview. J. Nat. Sci. Biol. Med. 4, 3-7 https://doi.org/10.4103/0976-9668.107253

Nicoletti I, Migliorati G, Pagliacci M.C, Grignani F, Riccardi C (1991): A rapid and simple method for measuring thymocyte apoptosis by propidium iodide staining and flow cytometry. J. Immunol. Methods 139, 271-279 https://doi.org/10.1016/0022-1759(91)90198-O

Nishimura Y, Oyama T. B, Sakanashi Y, Oyama T. M, Matsui H, Okano Y, Oyama Y (2008): Some characteristics of quercetininduced cytotoxicity on rat thymocytes under in vitro condition. Toxicol. In Vitro 22, 1002-1007 https://doi.org/10.1016/j.tiv.2008.02.006

Park GB, Choi Y, Kim YS, Lee HK, Kim D, Hur DY (2013): ROS and ERK1/2-mediated caspase- 9 activation increases XAF1 expression in dexamethasone-induced apoptosis of EBV-transformed B cells. Int. J. Oncol. 43, 29-38 https://doi.org/10.3892/ijo.2013.1949

Paul MV, Abhilash M, Varghese MV, Alex M, Harikumaran Nair R (2012): Protective effects of alphatocopherol against oxidative stress related to nephrotoxicity by monosodium glutamate in rats. Toxicol. Mech. Methods 22, 625-630 https://doi.org/10.3109/15376516.2012.714008

Pavlovic V, Cekic S, Ciric, Krtinic D, Jovanovic J (2016): Curcumin attenuates mancozeb-induced toxicity in rat thymocytes through mitochondrial pathway. Food Chem. Tox. 88, 105-111 https://doi.org/10.1016/j.fct.2015.12.029

Pavlovic V, Cekic S, Kocic G, Sokolovic D, Zivkovic V (2007a): Effect of monosodium glutamate on apoptosis and Bcl-2/Bax protein level in rat thymocyte culture. Physiol. Res. 56, 619-626
Pavlovic V, Pavlovic D, Kocic G, Sokolovic D, Jevtovic-Stoimenov T, Cekic S, Velickovic D (2007b): Effect of monosodium glutamate on oxidative stress and apoptosis in rat thymus. Mol. Cell. Biochem. 303, 161-166 https://doi.org/10.1007/s11010-007-9469-7

Rashid K, Sil PC (2015): Curcumin enhances recovery of pancreatic islets from cellular stress induced infla mMation and apoptosis in diabetic rats. Toxicol. Appl. Pharmacol. 282, 297-310 https://doi.org/10.1016/j.taap.2014.12.003

Reiner A, Levitz J, Isacoff EY (2015): Controlling ionotropic and metabotropic glutamate receptors with light: principles and potential. Curr. Opin. Pharmacol. 20, 135-143 https://doi.org/10.1016/j.coph.2014.12.008

Rezzani R, Corsetti G, Rodella L, Anqoscini P, Lonati C, Bianchi $R$ (2003): Cyclosporine-A treatment inhibits the expression of metabotropic glutamate receptors in rat thymus. Acta Histochem. 105, 81-87 https://doi.org/10.1078/0065-1281-00688

Sadek K, Abouzed T, Nasr S (2016): Lycopene modulates cholinergic dysfunction, Bcl-2/Bax balance, and antioxidant enzymes gene transcripts in monosodium glutamate (E621) induced neurotoxicity in a rat model. Can. J. Physiol. Pharmacol. 94, 394-401 https://doi.org/10.1139/cjpp-2015-0388

Sebastia N, Montoro A, Montoro A, Almonacid M, Villaescusa JI, Cervera J, Such E, Silla MA, Soriano MJ (2011): Assessment in vitro of radioprotective efficacy of curcumin and resveratrol. Radiat. Meas. 46, 962e966

https://doi.org/10.1016/j.radmeas.2011.05.009

Sharma A (2015): Monosodium glutamate-induced oxidative kidney damage and possible mechanisms: a mini-review. J. Biomed. Sci. 22, 93 https://doi.org/10.1186/s12929-015-0192-5

Singh MK, Yadav SS, Gupta V, Khattri S (2013): Immunomodulatory role of Emblica officinalis in arsenic induced oxidative damage and apoptosis in thymocytes of mice. BMC Complement. Altern. Med. 13, 193

https://doi.org/10.1186/1472-6882-13-193

Skerry TM, Genever PG (2001): Glutamate signalling in nonneuronal tissues. Trends Pharmacol. Sci. 22, 174-181 https://doi.org/10.1016/S0165-6147(00)01642-4

Storto M, Grazia U, Battaglia G, Felli MP, Maroder M, Gulino A, Raqona G, Nicoletti F, Screpanti I, Frati L, Calogero A (2000): Expression of metabotropic glutamate receptors in murine thymocytes and thymic stromal cells. J. Neuroimmunol. 109, $112-120$

https://doi.org/10.1016/S0165-5728(00)00269-1

Su CC, Lin YP, Cheng YJ, Huang JY, Chuang WJ, Shan YS, Yang BC (2007): Phosphatidylinositol 3-kinase/Akt activation by integrin-tumor matrix interaction suppresses Fas-mediated apoptosis in T cells. J. Immunol. 179, 4589-4597 https://doi.org/10.4049/jimmunol.179.7.4589

Wang ZB, Liu YQ, Zhang Y, Li Y, An XX, Xu H, Guo Y, Jin W, Jiang ZJ, Cui YF (2007): Reactive oxygen species, but not mitochondrial membrane potential, is associated with radiation-induced apoptosis of AHH-1 human lymphoblastoid cells. Cell Biol. Int. 31, 1353-1358 https://doi.org/10.1016/j.cellbi.2007.05.009 
Xue X, Yu JL, Sun DQ, Kong F, Qu XJ, Zou W, Wu J, Wang RM (2014): Curcumin induces apoptosis in SGC-7901 gastric adenocarcinoma cells via regulation of mitochondrial signaling pathways. Asian Pac. J. Cancer Prev. 15, 3987-3992 https://doi.org/10.7314/APJCP.2014.15.9.3987

Yu W, Zha W, Ke Z, Min Q, Li C, Sun H, Liu C.(2016): Curcumin protects neonatal rat cardiomyocytes against high glucoseinduced apoptosis via PI3K/Akt signalling pathway. J. Diabetes Res. 2016, 4158591 https://doi.org/10.1155/2016/4158591

Zhou Y, Tian L, Long L, Quan M, Liu F, Cao J (2013): Casticin potentiates TRAIL-induced apoptosis of gastric cancer cells through endoplasmic reticulum stress. PLoS One 8, e58855 https://doi.org/10.1371/journal.pone.0058855

Received: July 18, 2017

Final version accepted: October 16, 2017 